\title{
Joint report on the terminology for surgical procedures to treat stress urinary incontinence in women
}

\author{
Developed by the Joint Writing Group of the American Urogynecologic Society \\ and the International Urogynecological Association
}

Published online: 14 February 2020

(C) American Urogynecologic Society and International Urogynecological Association 2020

\begin{abstract}
Introduction and hypothesis Standardized terminology for surgical procedures commonly performed to treat stress urinary incontinence in women is needed to facilitate research, clinical care, and teaching in female pelvic medicine and reconstructive surgery. Methods This report combines the input of members of the American Urogynecologic Society and the International Urogynecological Association, assisted by external referees. Extensive searches of the literature were performed, including Instructions for Use brochures and original source documents where possible. Historical context was considered along with procedural modifications, and expert opinion was included when appropriate.

Results A terminology report for the procedures commonly performed to treat stress urinary incontinence in women was produced. Included procedures are midurethral sling, retropubic colposuspension, pubovaginal sling, urethral bulking, and artificial urinary sphincter. Appropriate figures have been included to supplement and help clarify the text. Ongoing review will be performed periodically to keep the document updated and widely acceptable.

Conclusions This document is a literature and consensus-based terminology report for surgical procedures to treat stress urinary incontinence in women. Future publications in female pelvic medicine and reconstructive surgery should use this standardized terminology whenever possible.
\end{abstract}

Keywords Stress urinary incontinence $\cdot$ Midurethral sling $\cdot$ Retropubic colposuspension $\cdot$ Pubovaginal sling $\cdot$ Urethral bulking · Artificial urinary sphincter

In the field of female pelvic medicine and reconstructive surgery (FPMRS), research is indispensable and necessary as advancements in surgical procedures are made. In addition, the practice of FPMRS, a field approached by trainees in urology as well as obstetrics and gynecology, requires teaching new learners from diverse backgrounds. Neither research nor teaching can be effective without language that has the same meaning to all involved stakeholders. For this reason, well-considered terminology

Individual contributors are noted in the Acknowledgments section.

This report is being published concurrently in Female Pelvic Medicine and Reconstructive Surgery and in International Urogynecology Journal. The report is identical except for minor stylistic and spelling differences in keeping with each journal's style. Citations from any of the two journals can be used when citing this article.

Correspondence: Sarah A. Collins, MD, Northwestern Medical Group, 250 E. Superior St, Ste. 5-2370, Chicago, IL 60611, USA.

E-mail: Sarah.Collins@nm.org surrounding major topics in FPMRS is essential. Stated simply, "The use of a common terminology is mandatory when experts from different branches of medicine have to cooperate." [1]

Surgical treatment of stress urinary incontinence, the "involuntary loss of urine on effort or physical exertion, or on sneezing or coughing," [2] has seen many changes since its inception. Surgical approach (abdominal vs vaginal), anatomic space (retropubic vs transobturator), and materials used (grafts, urethral bulking agents [UBAs] including particulate and nonparticulate materials, sutures or native tissue) vary widely between procedures. Furthermore, different eras in the history of FPMRS practice have seen some procedures, such as needle suspensions, become largely obsolete whereas others, such as midurethral slings, have become commonplace. For research to produce meaningful data about risks or efficacy of specific procedures, standardized and widely accepted terminology must be used. Each term must indicate 
to researchers, clinicians, and learners a specific and reliable set of steps.

The American Urogynecologic Society and the International Urogynecological Association aimed to produce a clinically based document that comprehensively assigns terms to widely practiced surgical procedures employed by obstetrician-gynecologists and urologists to treat stress urinary incontinence in women. Specifically, the authors sought to develop each term to:

1. Describe the procedure in clear language in a stepwise manner.

2. Include specific materials and equipment used in the procedure, if appropriate.

3. Include illustrations to clarify the procedure wherever possible.

4. Describe the mechanism of action through which the procedure is thought to restore continence.

5. Address, if appropriate, specific clinical scenarios or historical contexts in which the procedure is/was commonly practiced.

6. Be clinically meaningful in communications about surgeries between teachers and learners, researchers, clinicians, physiotherapists, and continence nurses.

The following terms are presented: midurethral sling, retropubic colposuspension, pubovaginal sling, urethral bulking, and artificial urinary sphincter. Acknowledgement of these standardized terms in written publications related to female pelvic floor disorders should be indicated in the Methods and Materials section, or its equivalent, to read as follows: methods, definitions, and units conform to the standards jointly recommended by the American Urogynecologic Society and the International Urogynecological Association, except where specifically noted.

The scope of this document was thoughtfully considered by the writing group, and there are many important topics relevant to a discussion about surgical procedures for the treatment of female stress urinary incontinence. To create a focused and meaningful terminology resource, we omitted topics beyond its scope such as data on clinical outcomes or recommendations regarding privileging and credentialing.

\section{Preoperative evaluation}

For women with uncomplicated stress urinary incontinence, which implies isolated stress urinary incontinence or stresspredominant mixed urinary incontinence, normal bladder emptying, urinalysis negative for urinary tract infection or hematuria, and the absence of pelvic organ prolapse past the hymen, the preoperative evaluation before surgery for stress incontinence can be performed in the office without multichannel urodynamic testing [3]. In women with stress urinary incontinence who do not meet these criteria, a more involved preoperative assessment, including urodynamic studies, may be necessary. Objective evidence of urine leakage with increased abdominal pressure should be documented before surgery for stress urinary incontinence. Incomplete bladder emptying and voiding dysfunction are relative contraindications to surgery, which could further impair emptying postoperatively. A cutoff postvoid residual volume of $150 \mathrm{~mL}$ has been suggested [4]. It is recommended that treatment of urinary tract infection and complete evaluation of hematuria, if diagnosed, be completed before the surgery for stress urinary incontinence [3]. Other factors to consider when selecting a surgical procedure for stress incontinence include immunodeficiency, history of pelvic radiation, or other impairments to healing, which may be contraindications to the use of synthetic materials. Appropriate perioperative medical management and standard antibiotic prophylaxis should be administered.

\section{Terminology report}

\section{Midurethral sling}

The midurethral sling is a vaginal surgery involving tensionfree placement of a type 1 polypropylene mesh strip, or tape, between the vagina and the urethra near its midpoint. Initially termed "intravaginal slingplasty," it was first introduced in a 1990 publication [5] by 2 urogynecologists, Australian Peter EP Petros and Scandinavian Ulf Ulmsten. The scientific basis of the procedure represented a departure from contemporary thinking and focused on the anatomic role of the vagina as the structural and functional support of the urethra and bladder neck. The original operation was described as a 2-staged office procedure under local anesthesia involving passage of a woven polyethylene terephthalate tape beneath the midurethra using "tunnelers," or trocars, passed retropubically. The tape was then removed 4 to 8 weeks later, and a "vaginal tuck" operation was performed. This involved excising 2 oblong, 1$\mathrm{cm}$-long areas of vaginal epithelium from either side of the urethra to "tighten" the suburethral vagina.

From the original prototype of the midurethral sling to the present-day versions, there has been an evolution in the permanent, implantable mesh material used as woven polyethylene terephthalate had a relatively high rate of symptomatic exposure of $8 \%$ [6]. Other materials [7] have been used with varying success, and modifications involving individualized, surgeon-cut mesh tapes also have been described [8]. With the now ubiquitous use of monofilament, macroporous Amid type 1 [9] polypropylene mesh in midurethral slings, exposure rates have decreased significantly [10]. The structure of type 1 
mesh allows improved tissue ingrowth compared with microporous and/or multifilament ones [11].

The first commercially available midurethral sling, the Tension-free Vaginal Tape (TVT, Gynecare; Ethicon, Somerville, NJ) was released in 1995 and was sold as a kit including a $1.1-\mathrm{cm}$-wide polypropylene tape, a reusable retropubic trocar, and a reusable catheter guide [12]. The procedure is performed by passing the trocar retropubically from the vagina to the suprapubic skin on either side of the urethra. The procedure soon became widely used in Europe and in the United States, and after a well-designed, multicentered, randomized controlled trial [13] revealed comparable safety and efficacy to retropubic colposuspension, midurethral sling became a commonly performed procedure for the treatment of stress urinary incontinence in women.

\section{Background}

Although the retropubic midurethral sling (RMUS) performed as above describes the original design, there are well-known modifications to the procedure that are practiced widely today (Fig. 1). In a variation on the RMUS, the trocars are passed from the suprapubic skin incisions down into the periurethral dissections, and the mesh is then drawn back through the path of the trocar on either side of the urethra. A variation in the path of the mesh through the bilateral obturator foramina instead of the retropubic space was described in 2001 with the purported advantage of avoiding blind passage of trocars into the retropubic space. The original transobturator midurethral sling was performed in an "outto-in" direction [14], in which the trocars pass from the skin laterally to the vaginal dissections medially. Soon after, an "into-out" transobturator procedure [15] was described in which the trocars pass the mesh tape laterally from the vaginal periurethral dissections to the skin.

Additional variations on the midurethral sling include single-incision and adjustable slings. These shorter slings are inserted using permanent anchors into the retropubic ("U configuration") or obturator ("H-" or "Hammock configuration") [16] tissues but do not pass all the way to the patient's skin.
Adjustable midurethral slings allow manipulation of the mesh days to weeks after surgical implantation [17]. Adjustable midurethral slings can be performed through the retropubic or transobturator approach and involve the implantation of a removable device at the time of surgery with planned followup in the office to tension the sling according to results of an awake cough stress test. This approach may be desirable for women with recurrent or persistent stress urinary incontinence after previous surgery.

\section{Preoperative considerations}

Patient counseling should address risks associated with any surgical procedure for stress urinary incontinence as well as those risks associated with the use of permanent mesh. The former risks include failure [18], voiding dysfunction, urinary retention, worsening or de novo urgency, urinary tract infection, and pain related to vaginal scarring. The latter includes mesh exposure through the vagina and into the lower urinary tract [4, 19]. Overall, patients should be reassured that midurethral sling surgery is safe and effective [3, 20,21]. A description regarding full-length midurethral sling procedures follows hereinafter.

\section{Anesthesia}

Midurethral sling is commonly performed under intravenous (IV) sedation, general anesthesia with endotracheal or laryngeal mask airway, and spinal anesthesia.

\section{Procedure description}

Equipment Midurethral slings are most commonly created and purchased as kits, which include a polypropylene mesh sling, sheathed temporarily in plastic, and trocar(s) needed to create a path for the mesh. Instruments needed for MUS placement include those found on a basic vaginal surgery tray and include a scalpel, fine scissors, tissue forceps, a needle driver, absorbable suture, any vaginal retractors deemed necessary by the surgical team, and a diagnostic cystoscope.
Fig. 1 Retropubic midurethral sling, pictured on the left; transobturator midurethral sling, pictured on the right
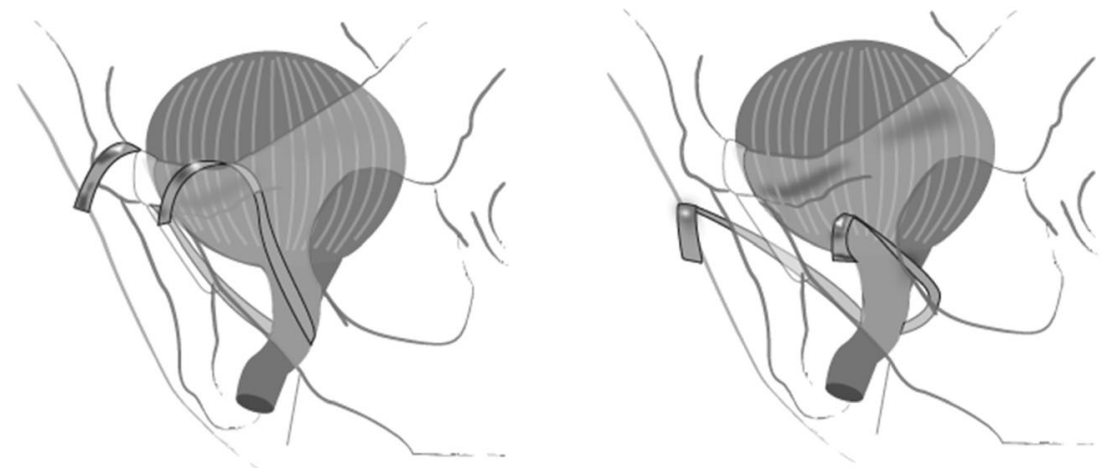


\section{Procedure}

- Step 1. With the patient in lithotomy position, the lower extremities are placed with either moderate (up to 60 degrees) flexion at the hips for a retropubic [22] approach or hyperflexion, with hips over the abdomen, for a transobturator [23] approach. Appropriate anesthesia is administered, and sterile preparation of the vagina, perineum, medial thighs, and suprapubic skin are performed. Prophylactic antibiotics are administered.

- Step 2. The bladder is drained, and an incision is made with the scalpel through the full thickness of the vagina beneath the midurethra.

- Step 3. Dissection is performed toward the retropubic or obturator spaces bilaterally to create tunnels through which the trocar(s) are passed. Some surgeons place a balloon catheter guide or cystoscope sheath at this point when performing the RMUS to deviate the urethra and bladder away from the path of the trocar(s) [24].

- Step 4. The sling is placed beneath the midurethra using the trocars, and cystourethroscopy is performed to confirm the absence of iatrogenic lower urinary tract injury during dissection and trocar passage. The vaginal tissue is inspected to evaluate for perforation.

- Step 5. The sling is positioned without tension. Surgeons have used various techniques for this including interposing various instruments between the urethra and the mesh. At this point, the plastic sheath is removed, allowing direct contact of the periurethral tissues with the mesh sling. The vaginal incision is closed over the sling with absorbable suture, and skin incisions are closed per surgeon preference.

For a procedure to meet the requirements implied by the term midurethral sling, the following must be performed: $(a)$ full thickness vaginal incision at the midurethra, (b) periurethral dissection, $(c)$ trocar passage and mesh placement beneath the midurethra, and $(d)$ positioning of the sling without tension and placement of the mesh in direct contact with the periurethral tissues. If the sling is placed in any location other than beneath the midurethra, if the trocars guide the mesh in any trajectory other than toward the retropubic or obturator tissues, or if the mesh is not Amid type 1 polypropylene, the procedure is not a midurethral sling.

\section{Safety}

When performing RMUS, surgeons must ensure passage of the trocar toward the patient's ipsilateral shoulder to avoid vascular injury [25]. Major hemorrhage due to vascular injury during transobturator midurethral sling placement is less likely [26]. Cystoscopy after placement of the sling trocars and before final positioning of the sling is recommended. Many surgeons assess for urinary retention before discharging patients after MUS. Patients should be educated about signs of postoperative complications such as voiding dysfunction and mesh exposure, and appropriate postoperative follow-up should be arranged.

\section{Technique variations}

Surgeons have adapted several methods that they feel improve safety and efficiency of midurethral sling performance. Some of these include hydrodissection of the suburethral vagina or planned trocar path with or without a local anesthetic and/or vasoconstrictive agent, use of slings developed with thinner trocar shafts, or use of self-retaining retractors [27].

\section{Retropubic Colposuspension}

Retropubic colposuspension is an abdominal or laparoscopic surgery involving dissection of the retropubic space in which the proximal urethra is elevated toward the retropubic periosteal fascia [28-30]. It can be performed laparoscopically, with or without robotic assistance, or through a laparotomy [31]. The procedure is thought to work by elevating and stabilizing the proximal urethra or bladder neck. The procedure was originally described as a technique that affixed the periurethral endopelvic fascia of the anterior vaginal wall and the urethral serosa to the pubic symphysis. This technique was called the Marshall, Marchetti, and Krantz procedure after the authors who published the original description. Rare cases of osteitis pubis due to suture placement into the posterior symphyseal periosteum occurred, however, and other points of fixation were sought. The most common alternative involves affixing the endopelvic fascia of the anterior vaginal wall just lateral to the proximal urethra to either the fascial periosteum of the retropubic surface of the pubic symphysis or to the pectineal ligament (Cooper's ligament), initially termed a Burch colposuspension.

\section{Background}

The original descriptions of retropubic colposuspension used suture, but modifications using mesh strips also have been described [32]. Another group of modifications, needle suspensions, were performed by passing needles through a suprapubic skin incision, then through the rectus fascia at its attachment to the pubic symphysis, and then down through the retropubic space. The suture then was attached to the periurethral portion of the endopelvic fascia of the anterior vaginal wall. The retropubic needle procedure initially was performed via open laparotomy and involved attaching the periurethral vaginal sutures to the underside of the rectus fascia in lieu of the retropubic periosteum. Eventually, the retropubic dissection was discarded as it was considered unnecessary, and the procedures were performed primarily 
through a vaginal approach [33]. Various fixation techniques, including the use of a synthetic bolster, have been described. The needle suspension procedures demonstrated poor longterm success rates and have largely been abandoned [34, 35].

\section{Preoperative considerations}

Patient selection and counseling may reflect the concept that patients who have stress urinary incontinence associated with urethral hypermobility may be better candidates for retropubic colposuspension, whereas those with fixed, nonhypermobile, low-pressure urethras may be poorer candidates. If the urethra is already well supported, there may be little additional benefit to affixing the urethra to a retropubic position [36].

\section{Anesthesia}

General anesthesia with a relaxed abdominal wall is often selected for the performance of this procedure, but it also can be performed under regional anesthesia.

\section{Procedure description}

Equipment These procedures can be done using an open abdominal or telescopic approach. Either an intraperitoneal or extraperitoneal dissection technique can be used. Standard gynecologic open abdominal and laparoscopic instrument trays are appropriate, and delayed-absorbable or permanent suture [37] is used. A diagnostic cystoscopy setup also is required.

\section{Procedure}

- Step 1. The patient is placed in low dorsal lithotomy position, and the vagina and abdomen are prepared and draped in a sterile fashion. A balloon catheter is placed.

- Step 2. Through either a low transverse incision or a telescopic approach, the retropubic space is entered, and the bladder is dissected away from the posterior symphysis pubis in the midline and laterally to expose the fascial periosteum and pectineal ligament. The bladder, urethra, urethrovesical junction, and periurethral endopelvic fascia of the anterior vaginal wall are identified. Identification of the urethra and urethrovesical junction can be aided applying gentle traction to the Balloon bulb at the bladder neck. The fascia can be identified by placing 2 fingers in the vagina and elevating the tissue just lateral and below the base of the transurethral balloon catheter.

- Step 3. Fatty areolar tissue overlying the anterior vaginal wall is gently dissected until the white, shiny endopelvic fascia beneath is visualized. Care should be taken to avoid vascular injury during this dissection.

- Step 4. On each side, 2 to 4 [38] permanent or delayedabsorbable sutures are placed in the endopelvic fascia of the anterior vaginal wall lateral to the bladder and urethra with the most distal sutures placed at the level of the midurethra or more proximally. Care must be taken not to enter the urethral lumen.

- Step 5. The sutures then are placed through the ipsilateral posterior periosteal fascia just lateral to the symphysis pubis (Fig. 2A) or through the ipsilateral pectineal ligament (Fig. 2B). If using the posterior periosteal fascia as a fixation point, the sutures can be tied down to bring about direct apposition of the endopelvic fascia and the posterior periosteal fascia. If the pectineal ligament is selected, a suture bridge is used to avoid excessive elevation of the periurethral tissues, which can result in urinary obstruction. Although different techniques use different numbers of sutures, there is some evidence that outcomes are better when at least 2 sutures are placed on each side [39].

- Step 6. Cystoscopic evaluation of the urethra and bladder is carried out to ensure no that injury to either of these structures has occurred.

To be considered a retropubic colposuspension, the procedure must involve $(a)$ dissection of the retropubic space and (b) fixation the anterior vaginal wall endopelvic fascia just lateral to the urethra to the posterior periosteal fascia of the pubic symphysis or the pectineal ligament.

\section{Safety}

The risk of vascular injury and significant blood loss can be mitigated by awareness of the relevant vascular anatomy. The retropubic space has many large venous structures, and there is a pampiniform plexus of venous channels in the endopelvic fascia. Brisk bleeding can be addressed with firm, direct pressure for several minutes. In addition, an aberrant obturator vein can traverse the pectineal ligament just lateral to the typical point of fixation. If present, this vessel should be avoided.

Lower urinary tract injury can result if the urethral sutures are inadvertently placed too medially. Stone formation on the sutures and irritative voiding symptoms can result. If permanent sutures are placed too deeply, they can perforate the vaginal mucosa and lead to chronic bleeding and discharge. If the periurethral tissue is excessively elevated, patients may experience obstructive voiding postoperatively.

\section{Pubovaginal sling}

A pubovaginal sling is an abdomino-vaginal surgery that uses a length of fascia, tissue, or graft to support the urethra with an abdominal wall fixation site (Fig. 3). The procedure originally was described in the early 20th century. The sling material is most commonly autologous and, therefore, the procedure has been referred to as a "fascial" sling; specifically, fascia from 
Fig 2 Retropubic

colposuspension. a, Sutures are passed through the endopelvic fascia lateral to the urethra and then through the posterior periosteal fascia of the pubic bone and tied down to bring tissue into direct apposition. $b$, Sutures are passed through the endopelvic fascia and then through the pectineal ligament. The sutures are bridged and not tied down
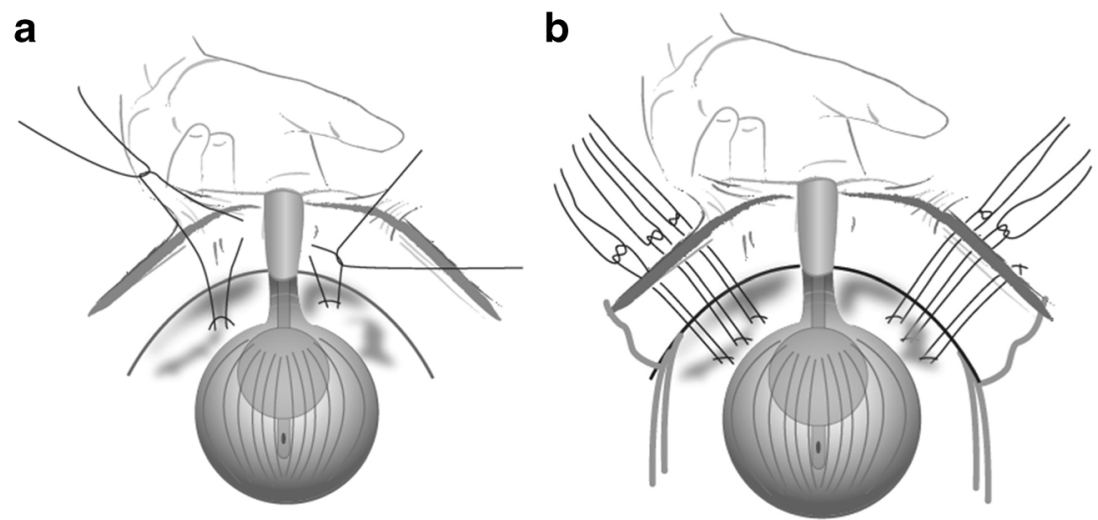

the rectus sheath or fascia lata has been used, but other materials (including allogenic, xenogenic, or synthetic grafts) have been described with varying success rates and complications.

\section{Background}

Giordano in 1907 described the use of the gracilis muscle wrapped around the urethra and over the next 10 years, the Goebell-Frangheim-Stoekel procedure evolved, using the pyramidalis, rectus fascia, or rectus muscle placed below the urethrovesical junction [40]. In 1933, Price used a strip of fascia lata below the urethra via a suprapubic approach with the free ends passed through and fixed to the rectus muscles [40]. The Aldridge sling was described in 1942 and involved dissection of 2 strips of rectus sheath, leaving the medial $2 \mathrm{~cm}$ of each side intact. The ends were passed down on either side of the urethra and sutured in an overlapping manner below it [41]. Beck et al [42] in 1974 referred to the Oxford technique of obtaining a strip of fascia lata measuring $1 \times 17 \mathrm{~cm}$ using a Wilson fascia stripper. McGuire and Lytton [43] in 1978 described a modification of the Aldridge sling, which involved fashioning a $1 \times 12$-cm strip of rectus sheath hinged on 1 side approximately $2 \mathrm{~cm}$ from the midline. The current iteration of the rectus fascia pubovaginal sling, initially described in the 1990s by Blavias and Jacobs [44] and McGuire et al. [45]), involves the use of a detached rectus sheath sling with free ends affixed to nonabsorbable (as Blavais described) or heavy absorbable (as McGuire described) suture, the so-called "sling on a string." [43]

Although autologous grafts commonly are used, allogenic grafts of fascia lata, usually harvested from cadavers, and Lyodura (homologous lyophilized dura mater) have been reported. Concerns regarding antigenicity and transmission of infection, such as HIV and slow viruses including CreutzfeldJacob disease, have been raised [40]. Xenogenic grafts include porcine dermis and small bowel porcine submucosa (SIS) also have been used as alternative grafts with lower success rates [46]. Synthetic slings were developed to avoid wound morbidity but had the risk of vaginal or urethral erosion. Examples include Silastic strips reinforced with Dacron, Mersilene (Ethicon), polyethylene, Polypropylene Marlex, and GoreTex (expanded polytetrafluoroethylene [40]).

A number of modifications of a technique for elevating the bladder neck using in situ sections of vaginal wall have been described. Termed "vaginal wall sling," the technique has more in common with needle suspension techniques than with
Fig 3 Pubovaginal sling. A longer length graft is used on the left, and the more modern "sling on a string" is pictured on the right side
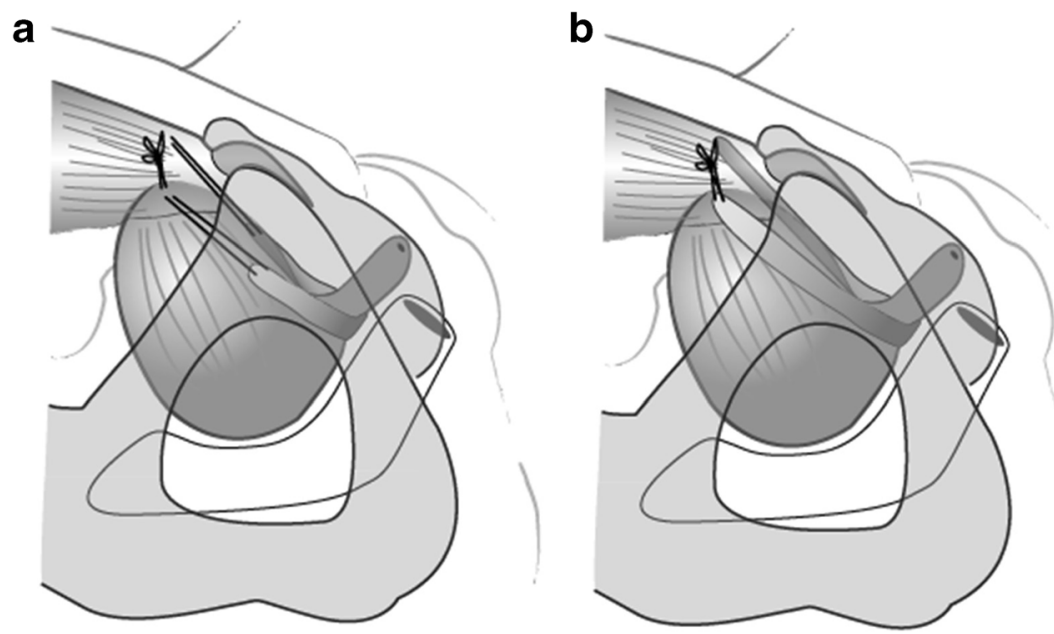
the pubovaginal sling [40]. A variant of this used bone anchors, made of permanent, often metal-containing materials, which attached either the periurethral tissue and vaginal wall or a synthetic sling to the pubic bone. Bone anchors avoided the need for an abdominal incision but were associated with infection and osteomyelitis $[47,48]$ and ultimately fell out of favor.

\section{Preoperative considerations}

Pubovaginal slings sometimes are used as primary procedures but often are performed as secondary procedures after other techniques have failed. They also are commonly selected for more complicated patients. There is a higher rate of postoperative voiding dysfunction [49] and wound morbidity than other stress urinary incontinence surgeries.

\section{Anesthesia}

Because an abdominal approach is required, general or regional anesthesia is required.

\section{Procedure description}

Equipment Basic laparotomy and vaginal surgical equipment trays and a diagnostic cystoscopic setup are required. Specialized instruments such as Stamey or Pereyra needles needle, a reusable MUS passer [50] to enable suture passage, or a Roberts clamp may be used to assist with passage of suture between the vaginal and retropubic dissection. If fascia lata pubovaginal sling is planned, a tendon stripper is likely to be required.

\section{Procedure}

- Step 1. The patient is placed in low lithotomy position, and a vaginal and abdominal prep is performed. A balloon catheter is placed. The vaginal and abdominal portions of the procedure can be done sequentially if there is 1 surgical team or simultaneously if 2 teams are available.

- Step 2. A transverse skin incision is made $2 \mathrm{~cm}$ above the pubic symphysis, and the rectus fascia is exposed. If using a rectus fascial graft, an area of rectus sheath measuring approximately $1.5-2 \times 8-10 \mathrm{~cm}$ is marked out and incised with cautery or a scalpel and then mobilized off the rectus muscles. The remaining fascia is mobilized sufficiently from the rectus muscles to facilitate closure at the end of the procedure. If fascia lata is used, the graft can be obtained with a tendon stripper from the lateral thigh, and a smaller low transverse abdominal incision can be used.

- Step 3. An absorbable or permanent monofilament suture is affixed to each free end of the graft and left long.
- Step 4. Vaginal dissection involves a 1.5- to 2-cm vertical incision under the urethra. Lateral periurethral tunnels are created with fine scissors, and the endopelvic fascia is perforated to create access to the retropubic space.

- Step 5. The sutures on the ends of the graft are passed on either side of the urethra using a long, fine clamp or specialized instrument described above by either a top-down or bottom-up approach. The center of the graft rests under the proximal to mid urethra, and the suture ends are passed through the lower aspect of the rectus sheath using a free needle. The sling may be secured to the urethra in the midline with suture.

- Step 6. If a rectus sheath graft was harvested, the resulting fascial incision is closed with absorbable sutures. The graft sutures ends are then tied across the midline of the rectus sheath with appropriate tension. Common techniques include interposing 2 fingers between the knot and fascia or placement of an intervening instrument such as scissors between urethra and graft before tying.

- Step 7. Cystoscopy is performed to ensure bladder integrity. The balloon catheter is replaced, and the vaginal incision is closed.

To be considered a pubovaginal sling, the procedure must involve the use of a graft that is passed beneath the proximal to midurethra and attached to the anterior abdominal wall.

\section{Safety}

Common complications include wound morbidity such as infection, and preoperative prophylactic antibiotics are particularly important for this reason. In addition, because the rectus fascia is opened for this procedure, and especially if the graft is harvested from the rectus sheath, an increased risk of incisional hernia in the future is conferred. Fibrosis created by previous retropubic procedures such as previous pubovaginal or midurethral slings, previous radiation, or history of retropubic hemorrhage may increase the risk of intraoperative complications such as lower urinary tract injury. Excessive tension on the graft may lead to short- or longterm voiding dysfunction. Surgical revision for wound morbidity has been reported in $3 \%$ of women who undergo pubovaginal sling and for voiding dysfunction in $6 \%$ [51].

\section{Technique variations}

Abdominal wound morbidity may be decreased by smaller abdominal incisions, especially possible when performing fascia lata slings. Using specialized devices to pass sutures between the vaginal and retropubic fields may decrease the risks associated with retropubic dissection. 


\section{Urethral bulking}

Urethral bulking refers to a transvaginal or transurethral surgery in which a substance is injected into the urethral submucosa at the bladder neck to facilitate coaptation. The aim is to achieve coaptation of the urethra during the storage phase of the micturition cycle and during phases of increased abdominal pressure to restore continence. In a continent sphincter, the urethral lining lies such that there is closure of the lumen at rest. This is achieved by the vascular and smooth muscle cushions, which are an integral component of the continence mechanism supporting the bladder base and urethra. When this mechanism fails, artificial cushioning can be created by injecting bulking agents into the area around the urethra. This increases the urethral resistance at rest while allowing it to remain patent during voiding.

\section{Types of UBAs}

Broadly speaking UBAs can be divided into 2 groups based on the characteristics of the substance injected.

Particulate UBAs These are composed of particles suspended in a biodegradable carrier gel.

- Macroplastique [52]: This is a silicone polymer and is made from highly textured poly-dimethyl-siloxane macroparticles suspended in a carrier gel of polyvinylpyrrolidione (povidone or PVP). The large particle diameter makes particle migration very unlikely.

- Durasphere [53]: This consists of carbon coated zirconium beads suspended in a polysaccharide carrier gel and was designed to reduce the risks of migration. It is durable and has a particle diameter of greater than 100 microns, making it comparable to collagen.

- Coaptite [54]: This is composed of calcium hydroxylapatite particles in an aqueous gel carrier and is nonimmunogenic as it is a normal constituent of bone.

Nonparticulate UBAs These are the following homogenous gels:

- Bulkamid [55]: This is a homogenous, hydrophilic gel consisting of $2.5 \%$ Polyacrylamide hydrogel and $97.5 \%$ water, which allows ingrowth of blood vessels originating from the periurethral tissue. It is biocompatible and durable.

Urethral injections first were described in 1938. In the early phases of development, autologous fat cells were harvested from the anterior abdominal wall, suspended in saline, and injected. This formulation underwent rapid lysis and migration after injection and hence was unsuitable for this purpose [56]. Other UBAs that were used in the early stages of development but later withdrawn from the market include Zuidex (hyaluronic acid with dextranomer) [53], Uryx (ethylene vinyl alcohol copolymer) [57], sodium morrhuate [58], Contigen [59], and polytetrafluoroethylene (Polytef paste) [60]. Zuidex was used initially for pediatric ureteral reflux and had an excellent safety profile but concerns about the formation of pseudo-abscess formation led to its withdrawal from the market. Uryx led to a high rate of urethral erosion, and Polytef had an unacceptably high particle migration rate. Contigen (glutaraldehyde cross-linked bovine collagen) was prepared by cross-linking bovine dermal collagen with glutaraldehyde and dispersed in a phosphate buffered physiological saline. Used widely until 2011, it was withdrawn by the manufacturers because of safety concerns as it was found to increase dysuria and urethral sloughing at the site of injection.

The complications associated with some bulking agents, the lower success rates compared with other surgical procedures for incontinence, and the relative ease of inserting midurethral slings have limited the use of UBAs. With growing media focus on complications associated with the use of mesh materials, midurethral slings are performed less frequently in some parts of the world. In these settings, UBAs have gained popularity, and research is ongoing to find more effective injectables that are as minimally invasive and as low risk as those currently available.

\section{Preoperative considerations}

Urethral bulking agent was initially proposed as a salvage procedure for women who were not candidates for major surgery or general anesthesia (Fig. 4). It is also an option for women who prefer to avoid surgery; that it is performed as an office procedure has made it more appealing. For younger women, it can be used in place of more definitive surgical treatment, which typically is reserved for after the completion of childbearing. It should not be used in women with bladder outlet obstruction, and this condition should be ruled out before UBA is offered. Patients with hypersensitivity to any of the ingredients in specific UBAs are not candidates for bulking with these agents. Bulking should not be performed in women with symptomatic urinary tract infections or bacteriuria.

\section{Anesthesia}

General anesthesia is not required. Urethral bulking often is performed under local anesthesia in an outpatient setting. Patients who prefer to undergo the procedure under general anesthesia may be offered this at the discretion of the surgeon after a discussion of the relative risks and benefits. 
Fig. 4 Urethral bulking. Transurethral injection is pictured on the left, and after the procedure, coaptation of the proximal urethra is achieved (right)

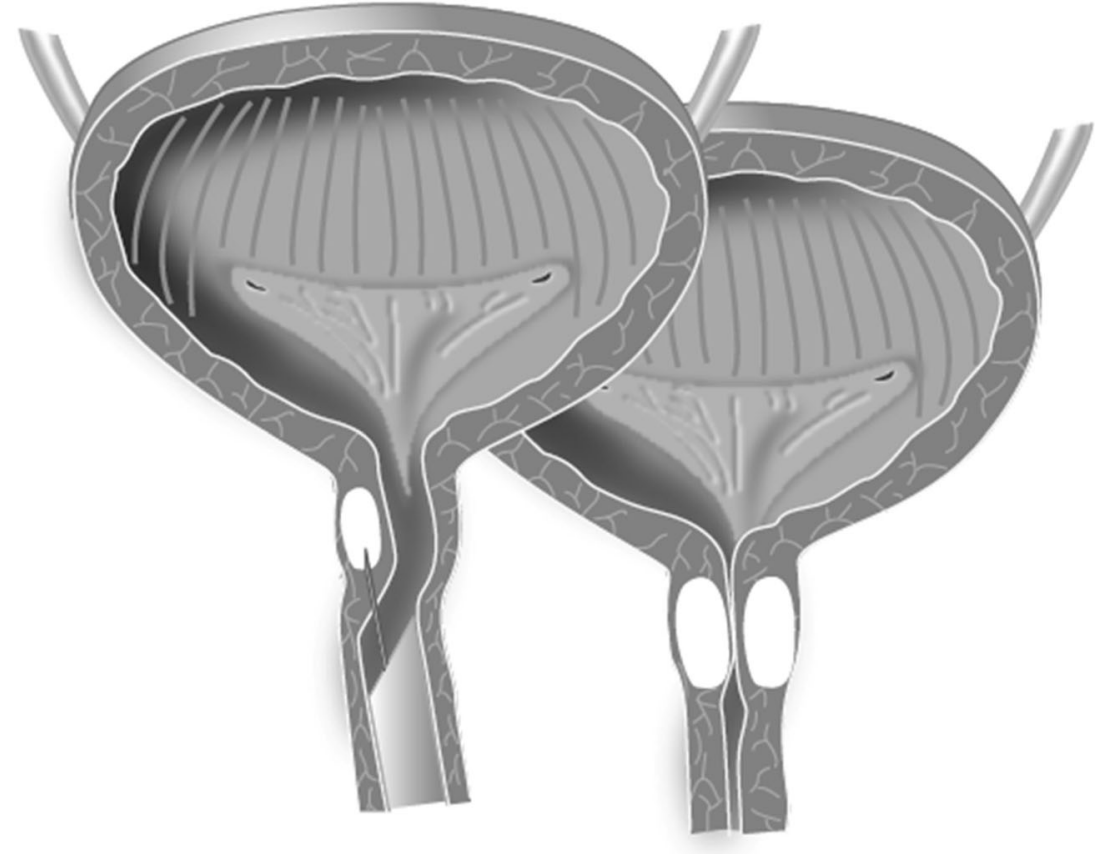

\section{Procedure description}

Equipment The equipment needed depends on the specific UBA used but includes, at a minimum, the bulking agent, a needle used for injection, which is specific to the agent being used, and a cystoscope.

\section{Procedure}

- Step 1. The patient is placed in the lithotomy position, and the table should be at a comfortable height so that injections can be undertaken while the clinician is seated. Anesthetic options include the instillation of $2 \%$ lidocaine gel directly into the urethra and/or the periurethral injection of local anesthetic into the sulci at the 3 and 9 o'clock positions.

- Step 2. The injection needle should be tightly secured to the syringe containing the injectable agent and should be primed before the injection.

- Step 3. Depending on the type of injectable used, injection can be performed either transurethrally or periurethrally.

a) Transurethral: This is the more common approach and is performed with direct endoscopic visualization of the urethral lumen. The primed injection needle is advanced down the operating channel of the cystoscope. With the cystoscope angled to 45 degrees, the needle is inserted at the midurethra so that the entire bevel is within the urethral submucosa. The angle of the scope then is altered so it is parallel to the urethra, a process called "tunneling." With the needle at the bladder neck, the material is injected. A visible bleb should form. A second injection is performed away from the previous injection site, and this is repeated until the bladder neck is visually closed.

b) Periurethral: This approach involves injecting on either side of the urethra from a vaginal approach and has the potential advantage of avoiding trauma to the urethral mucosa or leakage of the UBA into the urethral lumen. This can be achieved by using special devices to ensure correct placement of the UBA (macroplastique) or under direct cystoscopic guidance.

To be considered a UBA procedure, a specialized substance must be injected into the submucosa of the urethra at the bladder neck with confirmation of improved urethral coaptation after the procedure.

\section{Safety}

The ideal bulking agent should be nonimmunogenic and biocompatible and lead to minimal inflammatory or fibrotic tissue response. If using a particulate UBA, the size of the particles should be larger in diameter than $80 \mu \mathrm{m}$ to prevent particle migration. Patients should be informed of the possibility of voiding problems and urinary retention, which usually is selflimited but occasionally requires decompression with the narrowest catheter available. Temporary urgency incontinence, transient hematuria, and urinary tract infection also can occur.

\section{Technique variations}

The use of polyacrylamide hydrogel (Bulkamid) requires a short, 0-degree cystoscope specially designed for this product. 
It clicks onto a sheath that can rotate 360 degrees and holds the needle. Using the tunneling technique described previously, the UBA is injected into 3 to 4 sites, usually at the 2, 4, 8, and 10 o'clock positions, to coapt the bladder neck. Vessels should remain visible in the tissue to avoid necrosis and overfilling of the bladder should be avoided. After each injection, the needle can be retracted immediately without displacing the gel.

When using Macroplastique, transurethral injection requires the use of a specialized administration device, which holds the needle and the vial of the UBA and has a handheld lever for administering the product. This apparatus is connected to an operative cystoscope for the procedure. Periurethral injection of Macroplastique can be performed using another injection device that has been created by the manufacturer. It has 3 angled channels, which are evenly spaced around the circumference of the device that correspond to the planned injection sites in the urethra. The injection device is advanced to the level of the bladder neck, which is determined by fluid drainage from the urethra. Next, injections are placed through each of the device channels. When performed without an injection device, cystoscopic guidance is used, and implantation is confirmed when blebs are visualized at the bladder neck.

\section{Artificial urinary sphincter}

An artificial urinary sphincter (AUS) is an abdominal surgery in which a fully implantable prosthesis designed to reproduce the normal function of the urinary sphincter is placed (Fig. 5). It simulates the normal functioning of the urethral sphincter by opening and closing under patient control [61, 62]. Urethral occlusion is accomplished automatically and at physiologic pressures (approximately $60 \mathrm{~cm} \mathrm{H}_{2} \mathrm{O}$ ) by a fluid-containing occlusive cuff. These pressures are applied evenly around the bladder neck and proximal urethra. Urination is triggered voluntarily by the patient when she activates an implanted control pump located in the labia majora. This manipulation allows the transfer of the liquid contained in the occlusive cuff to a pressure-regulating balloon. The cuff remains open for a few minutes to allow urination and then pressurizes again automatically when the fluid returns from the balloon to the cuff, restoring urethral occlusion.

\section{Background}

The first implantation of an artificial urinary sphincter in humans was performed in 1972 by Brantley Scott on a 36year-old woman [63]. It consisted of the following 4 elements: a reservoir, an occlusive inflatable cuff, an inflation bulb, and a deflation bulb. The second version, launched in 1974, consisted of the following 3 elements: a pressure tank balloon, an occlusive cuff, and a pump, and it automatically repressurized after voids. In 1979, a third model was launched and included the current iteration of the pressure regulator

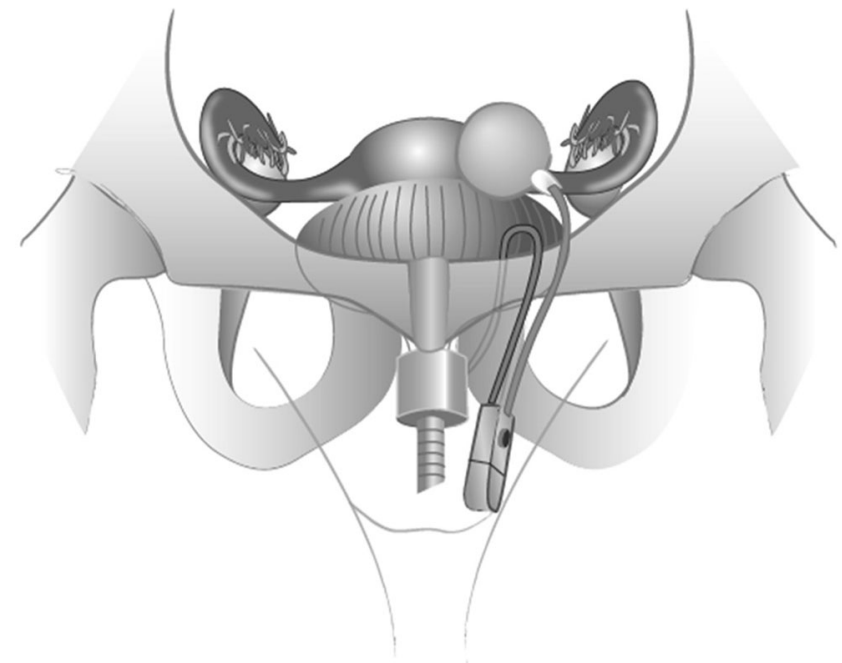

Fig. 5 Implanted artificial urinary sphincter (AMS 800)

balloon. This model was associated with a high rate of urethral erosion, especially during the immediate postoperative period. The currently used version (AMS800, created by American Medical Systems, Minnetonka, MN, and now sold by Boston Scientific, Marlborough, MA) made its original debut in 1983 but underwent several improvements until 1987, when the integration of an activation/deactivation system was developed to leave the cuff open during the postimplantation healing period [64].

\section{Preoperative considerations}

The AUS is intended for women with severe SUI, regardless of the etiology or mechanism (obstetric, neurogenic, iatrogenic, traumatic), after failure of other conservative and surgical treatment (MUS, UBAs) [62]. The implant is particularly indicated when there is significant urethral sphincter deficiency associated with a fixed urethra, and this is often best assessed with complex urodynamic testing and a thorough evaluation of urethral mobility. Another indication for AUS is advanced neurologic disease with an acontractile bladder in which urination occurs by Valsalva. Enlargement cystoplasty and placement of an AUS may be considered and can be performed concomitantly or in a staged manner $[63,65]$.

Several conditions must be met before an AUS can be considered. The bladder must adequately empty and fill at low pressures, and the patient must have the cognitive ability and manual dexterity to properly use her device. Relative contraindications to AUS include recurrent urinary tract infection, low bladder compliance, or intraoperative urethral or vaginal injury. In cases of prior pelvic irradiation, the postoperative erosion rate is more than $10 \%$ and the rate of urinary urgency and frequency is significantly higher [63].

Every effort should be made to minimize the risk of surgical site infection as infectious complications are common and 
often result in device explantation. Prophylaxis may include preoperative, intraoperative, and postoperative measures. Bacteriuria should be treated at least a week before the procedure; urine should be sterile at the time of the procedure to minimize the risk of septic complications.

\section{Anesthesia}

This procedure is performed under general anesthesia.

\section{Procedure description}

Equipment An open abdominal surgery tray including a scalpel, fine scissors, tissue forceps, a needle driver, absorbable suture, and retractors is needed. The device itself consists of 3 silicone elastomer components filled with a radiopaque solution. There is an outer occlusive cuff that is flexible but has a maximum volume. There is also an inner air-filled chamber that provides circumferential pressure. The cuff is $2 \mathrm{~cm}$ wide and exists in 12 lengths from 3.5 to $11 \mathrm{~cm}$. The length of the cuff is chosen preoperatively according to the dimensions of the implantation site and the specific characteristics of the patient. The occlusive cuff has a pressure-regulating balloon that exists in 5 pressure ranges (from 41 to $50 \mathrm{~cm} \mathrm{H}_{2} \mathrm{O}$ up to 81 to $90 \mathrm{~cm} \mathrm{H}_{2} \mathrm{O}$ ), tailored to the desired urethral pressure. The control pump measures approximately $1.2 \mathrm{~cm}$ wide and $3.3 \mathrm{~cm}$ long, and its upper part contains the mechanisms that transfer the solution to or from the cuff. The lower part of the pump is patient-controlled and opens the artificial sphincter for urination.

\section{Procedure}

- Step 1. The patient is placed in a lithotomy position and general anesthesia is administered. Sterile preparation of the abdomen, vagina, perineum, and medial thighs is performed. Prophylactic antibiotics are administered. A balloon catheter is placed in the urethra, and a low transverse abdominal incision is made with the scalpel $[62,66]$.

- Step 2. The retropubic dissection is initiated. This may be complicated by adhesions from prior procedures. Usually, the urethra is not visible and is inseparable from the anterior the vagina. Palpation of the balloon catheter and balloon can assist in locating the urethra and bladder neck. Dissection of the vesico-vaginal space must be performed meticulously. Using scissors with foam tips with 2 fingers placed intravaginally may be helpful. It is necessary to circumferentially dissect the urethra and bladder neck without damaging either structure or the vagina. A ruler may be used to evaluate the size of the cuff that will be positioned around the bladder neck. Selecting a cuff that is too short will cause voiding dysfunction. Choosing a cuff 0.5 to $1 \mathrm{~cm}$ larger than the measured value applies the correct amount of tension.
- Step 3. The control pump is placed in one of the patient's labia majora. This is the only part of the prosthesis accessible to the patient. The pressure regulator balloon is implanted in the paravesical space and allows the occlusive cuff in the closed position to provide circumferential pressures that are close to physiologic values. The implanted device is left inactive at the end of surgery to prevent erosion in the setting of perioperative edema.

- Step 4. A bladder catheter will remain in place for 3 to 4 days postoperatively, and antibiotic prophylaxis usually is recommended during this time. When the postoperative edema of the labium majorum into which the control pump is implanted is improved to the point that manipulation is not painful, the device may be activated. The gradual onset of a sphincter activation for approximately 1 month after implantation minimizes complications such as erosion.

For a procedure to meet the requirements implied by the term artificial urinary, the following must be performed: (a) retropubic approach to the dissection of the posterior urethra and bladder neck, $(b)$ positioning of a cuff around the bladder neck allowing urethral occlusion, (c) connection of the cuff to a control pump and a pressure-regulating balloon. If the device is placed in any location other than around the bladder neck, if the cuff around the bladder neck is not occlusive, and if it does not simulate the normal functioning of the urethral sphincter by opening and closing under patient control, the procedure is not an artificial urinary sphincter.

\section{Safety}

Published rates of the most common postoperative complications after placement of an AUS are as follows: infections (6.1\%), urethral erosions (7.5\%), and tissue atrophy $(6.1 \%)$ $[63,67,68]$. De novo overactive bladder syndrome with urgency urinary incontinence leading to recurrence of leakage without implant abnormalities has been reported in $4 \%$ of cases [69]. Major surgical complications resulting in explantation of the implant occurs in $20 \%$ of cases. Infections account for the majority of these $(5.5 \%)$ [63, 67, 70]. Erosion rates increase considerably with the number of previous interventions and with history of radiotherapy [67]. The postoperative infection rate is close to $9.5 \%$ when AUS is implanted at the time of augmentation cystoplasty [63].

\section{Technique variations}

The vaginal approach is rarely performed [66] but involves dissection of the bladder neck from an arcuate incision in the anterior vaginal wall a few centimeters proximal to the urethral meatus, and the AUS cuff is positioned under direct 
visualization. A small suprapubic incision is still needed to slide the balloon into the retropubic space. This technique is complicated by more infectious complications than the abdominal approach, and some authors believe that this technique does not allow positioning of the cuff proximally enough on the bladder neck $[66,67]$.

Several teams have recently shown the feasibility of AUS implantation either by laparoscopy [71, 72] and assistedrobotic laparoscopic approaches [73, 74]. These approaches could decrease intraoperative and postoperative complication rates, length of hospital stay, and blood loss, with similar continence and explantation rates [74].

Ongoing experimental testing of a new hydraulic artificial urinary sphincter in women [75] suggests that this device may be associated with fewer complications and may allow successful long-term control of urinary incontinence without the need for medical management [75].

\section{Summary}

- A midurethral sling is a vaginal surgery involving tensionfree placement of a type 1 polypropylene mesh strip, or tape, between the vagina and the urethra near its midpoint. Words delineating the path (retropubic or transobturator) and direction of the trocars can be used to more specifically describe the procedure.

- Retropubic colposuspension is an abdominal surgery involving dissection of the retropubic space in which the proximal urethra is elevated to the retropubic periosteal fascia or pectineal ligament. The location, type, and number of endopelvic fascial sutures should be specified. The retropubic fixation site also should be specified.

- A pubovaginal sling is an abdomino-vaginal surgery that uses a length of fascia, tissue, or graft to support the urethra with an abdominal wall fixation site.

- Urethral bulking refers to a transvaginal or transurethral surgery in which a substance is injected into the urethral submucosa at the bladder neck to augment it.

- Artificial urinary sphincter is an abdominal surgery in which a fully implantable prosthesis designed to reproduce the normal function of the urinary sphincter is placed.

\section{Conclusions}

The current surgical options for the management of stress urinary incontinence in women include midurethral sling, retropubic colposuspension, pubovaginal sling, urethral bulking, and artificial urinary sphincter. These terms should be used for research and didactic purposes going forward, and ongoing, periodic review of the literature will be performed to keep the terminology of these procedures updated.

Acknowledgments The following are being recognized for their contributions to this article: Sarah A. Collins, MD, (Northwestern University, Feinberg School of Medicine, Chicago, IL); Steven Swift, MD, (Medical University of South Carolina, Charlston, SC); Swati Jha, MD, (JessopWing, Sheffield Teaching Hospitals NHSFT, Sheffield, UK); Anna Rosamilia, MD (Monash University Department of Obstetrics and Gynecology, Monash Medical Center, Melbourne, Australia); Renaud de Tayrac, MD (Service de Gynécologie-Obstétrique, CHU Carémeau,Nîmes Cedex 9, France).

\section{Compliance with ethical standards}

Conflicts of interest S.A.C. is an expert witness from Ethicon / Johnson \& Johnson and an expert reviewer for medical guidelines clearinghouse. S.S. is a legal expert for Boston Scientific and a researcher local PI for Cook Myosite. A.R. is an Ethicon expert witness Boston scientific investigator led sponsored research grant. R.D.T. is a consultant for Boston Scientific and Coloplast. The contributors have declared they have no conflicts of interest.

\section{References}

1. Artibani W, Novara G. International continence society terminology for the lower urinary tract: the importance of standardization. Nat Clin Pract Urol. 2005;2(12):576-7.

2. Haylen BT, de Ridder D, Freeman RM. Et al; international Urogynecological association; international continence society. An international Urogynecological association (IUGA)/international continence society (ICS) joint report on the terminology for female pelvic floor dysfunction. Neurourol Urodyn. 2010;29(1):4 20.

3. Committee opinion: evaluation of uncomplicated stress urinary incontinence in women before surgical treatment. American Urogynecologic Society and American College of Obstetricians and Gynecologists. Female Pelvic Med Reconstr Surg. 2014;20: 248-51.

4. Nager CW, Brubaker L, Litman HJ, et al. A randomized trial of urodynamic testing before stress-incontinence surgery. N Engl J Med. 2012;366:1987-97.

5. Petros PE, Ulmsten UI. An integral theory of female urinary incontinence. Experimental and clinical considerations. Acta Obstet Gynecol Scand Suppl. 1990;153:7-31.

6. Wohlrab KJ, Erekson EA, Myers DL. Postoperative erosions of the Mersilene suburethral sling mesh for antiincontinence surgery. Int Urogynecol J Pelvic Floor Dysfunct. 2009;20(4):417-20.

7. Ford AA, Rogerson L, Cody JD, et al. Mid-urethral sling operations for stress urinary incontinence in women. Cochrane Database Syst Rev. 2017;7:Cd006375.

8. Rodriguez LV, Raz S. Prospective analysis of patients treated with a distal urethral polypropylene sling for symptoms of stress urinary incontinence: surgical outcome and satisfaction determined by patient driven questionnaires. J Urol. 2003;170(3):857-63.

9. Amid PK. Classification of biomaterials and their related complications in abdominal wall hernia surgery. Hernia. 1997;1(1):15-20.

10. Schimpf MO, Rahn DD, Wheeler TL, et al. Sling surgery for stress urinary incontinence in women: a systematic review and metaanalysis. Am J Obstet Gynecol. 2014;211(1):71.e1-e27.

11. Slack M, Sandhu JS, Staskin DR, et al. In vivo comparison of suburethral sling materials. Int Urogynecol J. 2006;17(2):106-10. 
12. Tension-free Vaginal Tape (TVT) System [Instructions for use, version 1]. Somerville, NJ: Gynecare, a division of Ethicon, Inc., a Johnson \& Johnson Company; 2009. Available at: https:// hostedvl106.quosavl.com/qb/. Accessed 05 November 2018.

13. Ward K, Hilton P; United Kingdom and Ireland Tension-free Vaginal Tape Trial Group. Prospective multicentre randomised trial of tension-free vaginal tape and colposuspension as primary treatment for stress incontinence. BMJ 2002;325(7355):67.

14. Delorme E. Transobturator urethral suspension: mini-invasive procedure in the treatment of stress urinary incontinence in women [in French]. Prog Urol. 2001;11(6):1306-13.

15. de Leval J. Novel surgical technique for the treatment of female stress urinary incontinence: transobturator vaginal tape inside-out. Eur Urol. 2003;44(6):724-30.

16. Molden SM, Lucente VR. New minimally invasive slings: TVT Secur. Curr Urol Rep. 2008;9(5):358-61.

17. Ugurlucan FG. Adjustable Midurethral Slings in the Treatment of Female Stress Urinary Incontinence. In: Alhasso A, ed. Synopsis in the Management of Urinary Incontinence. London: IntechOpen; 2017.

18. Richter HE, Litman HJ, Lukacz ES, et al. Demographic and clinical predictors of treatment failure one year after midurethral sling surgery. Obstet Gynecol. 2011;117(4):913-21.

19. Brubaker L, Norton PA, Albo ME, et al; Urinary Incontinence Treatment Network. Adverse events over two years after retropubic or transobturator midurethral sling surgery: findings from the Trial of Midurethral Slings (TOMUS) study. Am J Obstet Gynecol. 2011;205(5):498.e1-6.

20. Urinary incontinence in women. ACOG Practice Bulletin No. 155. American College of Obstetricians and Gynecologists Obstet Gynecol 2015;126(5):e66-81.

21. AUA. Position Statement on the use of vaginal mesh for the surgical treatment of stress urinary incontinence (SUI). Available at: https://www.auanetorg/guidelines/use-of-vaginal-mesh-for-thesurgical-treatment-of-stress-urinary-incontinence2013. Accessed 05 November 2018.

22. Gynecare TVT ${ }^{\mathrm{TM}}$ Obturator System [Instructions for Use]. Somerville, NJ: Gynecare, a division of Ethicon, Inc., a Johnson \& Johnson Company; 2015.

23. Swati J. Midurethral synthetic sling. In: Swati J, Ferriman E, eds. Medicolegal Issues in Obstetrics and Gynaecology. New York, NY; Springer. 2018:265-68.

24. Miranne JM, Dominguez A, Sokol AI, et al. Balloon catheter guide use during midurethral slings: does it make a difference? Can J Urol. 2015;22(3):7811-6.

25. Muir TW, Tulikangas PK, Fidela Paraiso M, et al. The relationship of tension-free vaginal tape insertion and the vascular anatomy. Obstet Gynecol. 2003;101:933-6.

26. Whiteside JL, Walters MD. Anatomy of the obturator region: relations to a trans-obturator sling. Int Urogynecol J Pelvic Floor Dysfunct. 2004;15(4):223-6.

27. Sokol ER. Rardin C. ObGyn News: Expert tips on retropubic vs. transobturator sling approaches; 2015. Available at: https://www. mdedge.com/obgyn/article/96687/surgery/expert-tips-retropubicvs-transobturator-sling-approaches. Accessed 05 November 2018.

28. Burch JC. Urethrovaginal fixation to Cooper's ligament for correction of stress incontinence, cystocele, and prolapse. Am J Obstet Gynecol. 1961;81:281-90.

29. Marshall VF, Marchetti AA, Krantz KE. The correction of stress incontinence by simple vesicourethral suspension. Surg Gynecol Obstet. 1949;88(4):509-18.

30. Tanagho EA. Colpocystourethropexy: the way we do it. J Urol. 1976;116(6):751-3.

31. Dean NM, Ellis G, Wilson PD, et al. Laparoscopic colposuspension for urinary incontinence in women. Cochrane Database Sys Rev. 2006;19(3):Cd002239.
32. Ankardal M, Ekerydh A, Crafoord K, et al. A randomised trial comparing open Burch colposuspension using sutures with laparoscopic colposuspension using mesh and staples in women with stress urinary incontinence. BJOG. 2004;111(9):974-81.

33. Cornella JL, Pereyra AJ. Historical vignette of Armand J. Peryra, MD, and the modified Pereyra procedure: the needle suspension for stress incontinence in the female. Int Urogynecol J 1990; (1):25-30.

34. Bodell DM, Leach GE. Needle suspension procedures for female incontinence. Urol Clin North Am. 2002;29(3):575-84.

35. Kobashi KC, Albo ME, Dmochowski RR, et al. Surgical treatment of female stress urinary incontinence: AUA/SUFU guideline. J Urol. 2017;198(4):875-83.

36. Nygaard IE, Heit M. Stress urinary incontinence. Obstet Gynecol. 2004;104(3):607-20.

37. NICE. Guideline NG 123: urinary incontinence and pelvic organ prolapse in women: management. Available at: https://www. niceorguk/guidance/NG123; 2019. Accessed 05 November 2018

38. Te Linde RW, Rock JA, Jones HW. TeLinde's operative Gynecology. 9th ed. Philadelphia, PA: Lippincott Williams \& Wilkins; 2003.

39. Souza RJ, Resende JAD. Júnior, Miglio CG, et al. can reducing the number of stitches compromise the outcome of laparoscopic Burch surgery in the treatment of stress urinary incontinence? Systematic review and meta-analysis. Rev Col Bras Cir. 2017;44(6):649-54.

40. Bidmead J, Cardozo L. Sling techniques in the treatment of genuine stress incontinence. BJOG. 2000;107(2):147-56.

41. Aldridge AH. Transplantation of fascia for relief of urinary stress incontinence. AJOG. 1942;44:398-411.

42. Beck RP, Grove D, Arnusch D, et al. Recurrent urinary stress incontinence treated by the fascia lata sling procedure. Am J Obstet Gynecol. 1974;120(5):613-21.

43. McGuire EJ, Lytton B. Pubovaginal sling procedure for stress incontinence. J Urol. 1978;119(1):82-4.

44. Blaivas JG, Jacobs BZ. Pubovaginal fascial sling for the treatment of complicated stress urinary incontinence. J Urol. 1991;145(6): 1214-1218.

45. Cross CA, Cespedes RD, McGuire EJ. Our experience with pubovaginal slings in patients with stress urinary incontinence. $\mathrm{J}$ Urol. 1998;159(4):1195-1198.

46. Broussard AP, Reddy TG, Frilot CF, et al. Long-term follow-up of porcine dermis pubovaginal slings. Int Urogynecol J. 2013;24(4): 583-7.

47. Fialkow MF, Lentz GM, Miller EA, et al. Complications from transvaginal pubovaginal slings using bone anchor fixation. Urology. 2004;64(6):1127-32.

48. Goldberg RP, Tchetgen MB, Sand PK, et al. Incidence of pubic osteomyelitis after bladder neck suspension using bone anchors. Urology. 2004;63(4):704-8.

49. Rehman $\mathrm{H}$, Bezerra CA, Bruschini $\mathrm{H}$, et al. Traditional suburethral sling operations for urinary incontinence in women. Cochrane Database of Sys Rev. 2017;7:CD001754.

50. Mahdy A, Ghoniem GM. Autologous rectus fascia sling for treatment of stress urinary incontinence in women: a review of the literature. Neurourol Urodyn 2019;38Suppl 4;S51-8.

51. Albo ME, Richter HE, Brubaker L, et al. Burch colposuspension versus fascial sling to reduce urinary stress incontinence. N Engl J Med. 2007;356(21):2143-55.

52. Ghoniem GM, Miller CJ. A systematic review and meta-analysis of macroplastique for treating female stress urinary incontinence. Int Urogynecol. 2013;24(1):27-36.

53. Lightner DJ, Itano NB, Sweat SD, et al. Injectable agents: present and future. Curr Urol Rep. 2002;3(5):408-13.

54. Mayer RD, Dmochowski RR, Appell RA, et al. Multicenter prospective randomized 52-week trial of calcium hydroxylapatite versus bovine dermal collagen for treatment of stress urinary incontinence. Urol. 2007;69(5):876-80. 
55. Kasi AD, Pergialiotis V, Perrea DN, et al. Polyacrylamide hydrogel (Bulkamid(R)) for stress urinary incontinence in women: a systematic review of the literature. Int Urogynecol J. 2016;27(3):367-75.

56. Lee PE, Kung RC, Drutz HP. Periurethral autologous fat injection as treatment for female stress urinary incontinence: a randomized double-blind controlled trial. J Urol. 2001;165(1):153-8.

57. Hurtado E, McCrery R, Appell R. The safety and efficacy of ethylene vinyl alcohol copolymer as an intra-urethral bulking agent in women with intrinsic urethral deficiency. Int Urogynecol J Pelvic Floor Dysfunct. 2007;18(8):869-73.

58. Zoorob D, Karram M. Bulking agents: a urogynecology perspective. Urol Clin North Am. 2012;39(3):273-7.

59. Chaliha C, Williams G. Periurethral injection therapy for the treatment of urinary incontinence. Br J Urol. 1995;76(2):151-5.

60. Sangster P, Morley R. Biomaterials in urinary incontinence and treatment of their complications. Indian J Urol. 2010;26(2):221-9.

61. Kowalczyk JJ, Mulcahy JJ. Use of the artificial urinary sphincter in women. Int Urogynecol J Pelvic Floor Dysfunct. 2000;11(3):176-9.

62. Costa P, Mottet N, Rabut B, et al. The use of an artificial urinary sphincter in women with type III incontinence and a negative Marshall test. J Urol. 2001;165(4):1172-6.

63. Petrou SP, Elliott DS, Barrett DM. Artificial urethral sphincter for incontinence. Urology. 2000;56(3):353-9.

64. Maillet F, Buzelin JM, Bouchot $\mathrm{O}$, et al. Management of artificial urinary sphincter dysfunction. Eur Urol. 2004;46(2):241-5.

65. Phe V, Leon P, Granger B, et al. Stress urinary incontinence in female neurological patients: long-term functional outcomes after artificial urinary sphincter (AMS 800(TM)) implantation. NeurourolUrodyn. 2017;36(3):764-9.

66. Elliott DS, Barrett DM. The artificial urinary sphincter in the female: indications for use, surgical approach and results. Int Urogynecol J Pelvic Floor Dysfunct. 1998;9(6):409-15.

67. Venn SN, Greenwell TJ, Mundy AR. The long-term outcome of artificial urinary sphincters. J Urol. 2000;164:702-6.
68. Costa P, Poinas G, Ben Naoum K, et al. Long-term results of artificial urinary sphincter for women with type III stress urinary incontinence. Eur Urol. 2013;63(4):753-8.

69. Roupret M, Chartier-Kastler E, Almeras C, et al. Sacral neuromodulation for refractory detrusor overactivity in women with an artificial urinary sphincter. J Urol. 2004;172(1):236-9.

70. Richard F, Lefort J, Bitker M, et al. Female incontinence with primary sphincter deficiency: results of artificial urinary sphincter (AMS 800) with long-term follow-up. J Urol. 1996;155:1568.

71. Saffarian A, Walsh K, Walsh IK, et al. Urethral atrophy after artificial urinary sphincter placement: is cuff downsizing effective? J Urol. 2003;169(2):567-9.

72. Roupret M, Misrai V, Vaessen C, et al. Laparoscopic approach for artificial urinary sphincter implantation in women with intrinsic sphincter deficiency incontinence: a single-Centre preliminary experience. Eur Urol. 2010;57(3):499-504.

73. Biardeau X, Rizk J, Marcelli F, et al. Robot-assisted laparoscopic approach for artificial urinary sphincter implantation in 11 women with urinary stress incontinence: surgical technique and initial experience. Eur Urol. 2015;67(5):937-42.

74. Peyronnet B, Vincendeau S, Tondut L, et al. Artificial urinary sphincter implantation in women with stress urinary incontinence: preliminary comparison of robot-assisted and open approaches. Int Urogynecol J. 2016;27(3):475-81.

75. Morgan K, Milner HR, Tikekar A, et al. Long term use of hydraulic artificial urethral sphincters in nine dogs from New Zealand with urethral sphincter mechanism incompetence. N Z Vet J. 2018;66(4): 205-9.

Publisher's note Springer Nature remains neutral with regard to jurisdictional claims in published maps and institutional affiliations. 